\title{
Erratum to: Benefits and unexpected artifacts of biplanar digital slot-scanning imaging in children
}

\author{
Steven L. Blumer • David Dinan • Leslie E. Grissom
}

Published online: 28 March 2014

(C) Springer-Verlag Berlin Heidelberg 2014

Erratum to: Pediatr Radiol

DOI 10.1007/s00247-014-2908-1

In the section on Movement artifacts, an observation by the authors was attributed to "personal communication, Sophie Pastre, EOS Imaging." This reference should be attributed to personal communication, EOS imaging. Ms. Pastre did not give her explicit permission to reference her name in this manuscript.

The online version of the original article can be found at http://dx.doi.org/ 10.1007/s00247-014-2908-1.

S. L. Blumer $(\bowtie)$

Department of Medical Imaging,

Nemours/A.I duPont Hospital for Children, 1600 Rockland Road,

Wilmington, DE 19803, USA

e-mail: sblumer@nemours.org

D. Dinan

Nemours Children's Hospital, Orland, FL, USA

\section{E. Grissom}

Department of Radiology,

Nemours/Alfred I. duPont Hospital for Children,

Wilmington, DE, USA 